\title{
Correlation of neck and wrist circumference with waist circumference
}

\author{
B B Karki*, M D Bhattarai, M R Bajracharya, S Karki, A R Devkota \\ National Academy of Medical Sciences, Bir Hospital, Kathmandu, Nepal
}

\section{DOI Name \\ http://dx.doi.org/10.3126/jaim.v3i2.14063}

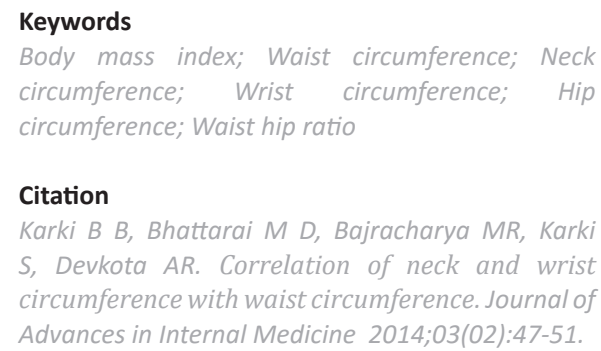

\section{Citation}

Karki B B, Bhattarai M D, Bajracharya MR, Karki $S$, Devkota AR. Correlation of neck and wrist circumference with waist circumference. Journal of Advances in Internal Medicine 2014;03(02):47-51.

\begin{abstract}
Background and aims: Body mass index, waist and hip circumference have been using for measurement of obesity, however practically it's difficult to get these measures accurately because of the various reasons, so an alternativeto this could be neck and wrist circumference measurement. As there is scarce report on such anthropometric studies from Nepal, we aimed to find out the correlation between neck and wrist circumference with waist circumference for obesity measure.
\end{abstract}

Method: A cross sectional observational study of total 297 (147 male and 150 female) participants, aged above 18 years conducted on 2013 at Kathmandu valley. Anthropometric markers of obesity were measured, including body weight, height, waist, hip, neck and wrist circumferences.

Results: A strong positive Pearson correlation of neck circumference with waist circumference was found in both male and females $(r=0.64$ in male and $r=0.86$ in female). Neck circumference had strong positive correlation with waist circumference in obese female than in male $(r=0.5$ in male and $r=0.82$ in female).Similarly, neck circumference had positive correlation with body mass index( $r=0.53$ in male and $r=0.79$ in female), hip( $r=0.54$ in male and $r=0.76$ in female), weight $(r=0.59$ in male and $r=0.77$ in female) except waist hip ratio( $r=0.59$ in male and $r=0.10$ in female). Neck circumference cutoff for abnormal waist ( $\geq 90 \mathrm{~cm}$ for male and $\geq 80 \mathrm{~cm}$ for female) was $34.4 \mathrm{~cm}$ for male and $32.5 \mathrm{~cm}$ for female. Similarly wrist circumference had also positive correlation with waist circumference $(r=0.58$ and $r=0.64$ in female) and with weight $(r>0.6)$ in both sexes.

Conclusion: Neck circumference which can be relatively easily measured has shown strong correlation with waist.

\section{INTRODUCTION}

Obesity is rapidly growing in both developed and developing country. ${ }^{1}$ Visceral obesity is linked with insulin resistance, hypertension and dyslipidemia and is related to increased risk of type 2 diabetes and cardiovascular diseases. ${ }^{2,3}$

BMI has been adopted by most health professionals for obesity surveys, as it is easy to perform on a large scale. However, it does not depict the true body composition. Furthermore, visceral obesity, which closely relates to cholesterol levels in the body and its association with coronary artery disease, is better defined by measuring the waist circumference. ${ }^{4}$ Waist circumference is considered as an important component for the diagnosis of metabolic syndrome. ${ }^{5}$ But practically it's difficult to get the accurate measurement of waist because of the various reasons like: inadequate exposure of body

\footnotetext{
* Corresponding author

Dr Budda Bahadur Karki

National Academy of Medical Sciences, Bir Hospital, Kathmandu, Nepal Email: buddabdrkarki@gmail.com
} 
especially in winter, in busy, everyday primary care practice, site of measurement etc. so alternative to this measurement for a practical point of view is needed.

Some studies demonstrated that NC (neck circumference) is an index of upper body fat distribution that can be used to identify obese patients. ${ }^{6-10}$ In some studies, NC is also found to be related to cardiovascular risk factors in severely obese men and women. ${ }^{6}$ There is not enough data in the literature evaluating the eligibility of wrist circumference as an obesity parameter. ${ }^{11}$ Marco Capizzi et al found a close relationship among wrist circumference, its bone component, and insulin resistance in overweight/obese children and adolescents, opening new perspectives in the prediction of cardiovascular disease. ${ }^{12}$ Measurement of neck circumference has recently been used to identify overweight and obesity and is observed to have good correlation with age, weight, waist and hip circumferences, waist-to-hip ratio, and BMI for both genders. ${ }^{13}$

Nepal belongs to the south Asian region where the noncommunicable diseases like diabetes mellitus, metabolic disorders and cardio vascular disorders are increasing in number day by day.

Increment of problem of diabetes in Nepal was also shown by the clustered-sampled population-based study of the urban areas of Nepal conducted between 2001 to 2002 where out of the total population, $30.5 \%$ (37.8\% of men and $25.3 \%$ of women) had some abnormality of glucose tolerance. ${ }^{14} \mathrm{As}$ the obesity is preventable condition which in future can lead to diabetes and cardio vascular diseases, anthropometry can be one of the useful and easy tools for its early recognition. Measurement of neck circumference may improve prediction of incident diabetes over traditional adiposity measures such as BMI and waist circumference. ${ }^{15}$

As there is scarce report on the anthropometric measurements of Nepalese population, we decided to perform anthropometric evaluation of Nepalese population.In this study we aimed to determine wrist and neck circumference as alternatives for measurement for diagnosis of obesity and correlate them with waist circumference in different BMI categories.

\section{METHOD}

An observational cross-sectional study of 297 healthy participants above 18 years of age conducted on 2013. Participants were recruited as convenient sample from different parts of Kathmandu valley.Written informed consent was obtained from all participants and clearance was taken from the Institutional review board of National academy of medical sciences. All the participants were examined for the presence of confounding variables like abdominal distension, neck fullness or swelling, and wrist deformity or fracture and, if found positive, were excluded from the study.

Anthropometric markers were measured, including body weight, height, waist, hip, neck and wrist circumferences using standard techniques ${ }^{16}$ as: Body weight and height were measured while wearing light clothing and without shoes and BMI were calculated.Waist circumference $(\mathrm{cm})$ was taken horizontally to within $1 \mathrm{~mm}$, using plastic tape measure at midpoint between the costal margin and iliac crest in the mid-axillary line, with the subject standing and at the end of normal expiration. Hip circumference was measured at the level of greater trochanters, with the legs close together. The WHR was calculated by the division of waist circumference to hip circumference as an index of central obesity.The neck circumference $(\mathrm{cm})$ was taken in a plane as horizontal as possible, at a point just below the larynx (thyroid cartilage) and perpendicular to the long axis of the neck (the tape line in front of the neck at the same height as the tape line in the back of the neck). Wrist circumference was measured from both right and left wrists at the wrist crease distal to the styloid processes and an average was taken. All circumferences were taken in fasting state with the subjects standing upright and shoulders relaxed. The tape rests firmly on the skin without compressing the skin. The circumference was measured to the nearest 0.1 $\mathrm{cm}$.The average of the two measures was used for the analysis. The participants were categorized in two group normal BMI and abnormal BMI group. Normal BMI was considered if it is in the range of 18 to $22.9 \mathrm{~kg} / \mathrm{m} 2$ and abnormal BMI if it is $\geq 23 \mathrm{~kg} /$ $\mathrm{m} 2$ or $<18 \mathrm{~kg} / \mathrm{m} 2$ and abnormal waist cutoff ( $\geq 80 \mathrm{~cm}$ for female and $\geq 90 \mathrm{~cm}$ for male) as specified for Indian Asian population. ${ }^{5}$

Statistical analyses were performed using SPSS 17.0. All results were expressed as mean standard deviation (SD) or frequency ( $n$ \%) or range where appropriate. Pearson's correlation coefficient was performed between neck circumference and waist circumference in normal and abnormal BMI males and females separately. A $p$ value $<0.05$ was considered to be significant.

\section{RESULTS}

Out of 297 Participants, $147(49.4 \%)$ were males and 150(50.6\%) were females. Normal range BMI of 18 to $22.9 \mathrm{~kg} / \mathrm{m} 2$ was found in $40 \%$ of participants, $\mathrm{BMl}$ of $<18 \mathrm{~kg} / \mathrm{m} 2$ (underweight) in $1.68 \%, \mathrm{BMI}$ of $\geq 23 \mathrm{~kg} / \mathrm{m} 2$ (overweight) in $18.5 \%$ and $\mathrm{BMI}$ of $\geq 25 \mathrm{~kg} / \mathrm{m}$ 2(obesity) in $39.7 \%$ participants. Mean age of male and female participants were $31.6 \pm 10.3 y e a r s$ and $34.4 \pm 9.9$ years respectively. Other general characteristics of participants were shown in table 1 . Statistical significant difference was noted in BMI, height, waist circumference and wrist circumference between male and female where female had 
relatively higher $\mathrm{BMI}$, and waist circumference but height and wrist circumference was higher in male participants.

Table 1. General Characteristics of the subjects

\begin{tabular}{|c|c|c|c|}
\hline Parameters & $\begin{array}{c}\text { Male (Mean } \\
\qquad \begin{array}{c}( \pm S D) \\
(n=147)\end{array}\end{array}$ & $\begin{array}{l}\text { Female ( } \\
\text { Mean ( } \pm S D) \\
(n=150)\end{array}$ & $P$ value \\
\hline Height(m) & $1.67 \pm 0.08$ & $1.55 \pm 0.09$ & $<0.001$ \\
\hline Weight(kg) & $67.78 \pm 13.30$ & $64.11 \pm 13.13$ & 0.018 \\
\hline $\mathrm{BMI}(\mathrm{kg} / \mathrm{m} 2)$ & $24.28 \pm 4.46$ & $26.56 \pm 4.68$ & $<0.001$ \\
\hline Waist circumference $(\mathrm{cm})$ & $84.30 \pm 11.08$ & $89.48 \pm 11.10$ & $<0.001$ \\
\hline Neck circumference $(\mathrm{cm})$ & $34.61 \pm 5.49$ & $35.21 \pm 3.47$ & 0.262 \\
\hline Hip circumference $(\mathrm{cm})$ & $94.09 \pm 7.03$ & $96.73 \pm 8.91$ & 0.005 \\
\hline Waist hip ratio & $0.89 \pm 0.06$ & $0.90 \pm 0.09$ & 0.197 \\
\hline Wrist circumference $(\mathrm{cm})$ & $16.44 \pm 0.97$ & $15.71 \pm 0.93$ & $<0.001$ \\
\hline
\end{tabular}

A strong positive correlation of neck circumference was found with waist circumference and BMI in both males and females and positive correlation was found with hip circumference and weight (Table 2).

Table 2. Pearson Correlation of neck circumference $(\mathrm{cm})$ with other anthropometric measures

\begin{tabular}{lccccc}
\hline & \multicolumn{2}{c}{ Male(n=147) } & \multicolumn{3}{c}{ Female( $\mathrm{n}=150)$} \\
\multicolumn{1}{c}{ Variables } & $\begin{array}{c}\text { Pearson } \\
\text { coefficient } \\
(\mathbf{r})\end{array}$ & $\begin{array}{c}\text { P } \\
\text { value }\end{array}$ & $\begin{array}{c}\text { Pearson } \\
\text { coefficient } \\
(\mathbf{r})\end{array}$ & P value \\
\hline Waist circumference $(\mathrm{cm})$ & 0.64 & $<0.001$ & 0.86 & $<0.001$ \\
BMI (kg/m2) & 0.53 & $<0.001$ & 0.79 & $<0.001$ \\
Hip circumference $(\mathrm{cm})$ & 0.54 & $<0.001$ & 0.76 & $<0.001$ \\
Weight $(\mathrm{kg})$ & 0.59 & $<0.001$ & 0.77 & $<0.001$ \\
WHR & 0.59 & $<0.001$ & 0.10 & 0.228 \\
Height $(\mathrm{m})$ & 0.18 & 0.025 & 0.17 & 0.039 \\
\hline
\end{tabular}

Wrist circumference had positive correlation with weight, BMI waist and hip circumference in both males and females (Table 3). Figure.1 showed a correlation of neck circumference with waist in different BMI categories ( $\leq 22.9 \mathrm{~kg} / \mathrm{m} 2$ and $\geq 23 \mathrm{~kg}$ / $\mathrm{m} 2$ ) where a strong positive correlation was found between neck circumference and waist in females with $\mathrm{BMI} \geq 23 \mathrm{~kg} /$ $\mathrm{m} 2(r=0.82)$ than in males $(r=0.57)$ with same BMI.
Table 3. Pearson Correlation of wrist circumference $(\mathrm{cm})$ with other anthropometric measures

\begin{tabular}{|c|c|c|c|c|}
\hline \multirow[b]{2}{*}{ Variables } & \multicolumn{2}{|c|}{ Male(n=147) } & \multicolumn{2}{|c|}{ Female(n=150) } \\
\hline & $\begin{array}{c}\text { Pearson } \\
\text { coefficient } \\
\text { (r) }\end{array}$ & $\begin{array}{c}P \\
\text { value }\end{array}$ & $\begin{array}{l}\text { Pearson } \\
\text { coefficient } \\
\text { (r) }\end{array}$ & $\begin{array}{c}P \\
\text { value }\end{array}$ \\
\hline Weight(kg) & 0.75 & $<0.001$ & 0.83 & $<0.001$ \\
\hline $\mathrm{BMI}(\mathrm{kg} / \mathrm{m} 2)$ & 0.62 & $<0.001$ & 0.60 & $<0.001$ \\
\hline Waist circumference $(\mathrm{cm})$ & 0.58 & $<0.001$ & 0.64 & $<0.001$ \\
\hline Hip circumference $(\mathrm{cm})$ & 0.56 & $<0.001$ & 0.66 & $<0.001$ \\
\hline WHR & 0.44 & $<0.001$ & 0.13 & 0.101 \\
\hline Height(m) & 0.36 & $<0.001$ & 0.55 & $<0.001$ \\
\hline
\end{tabular}

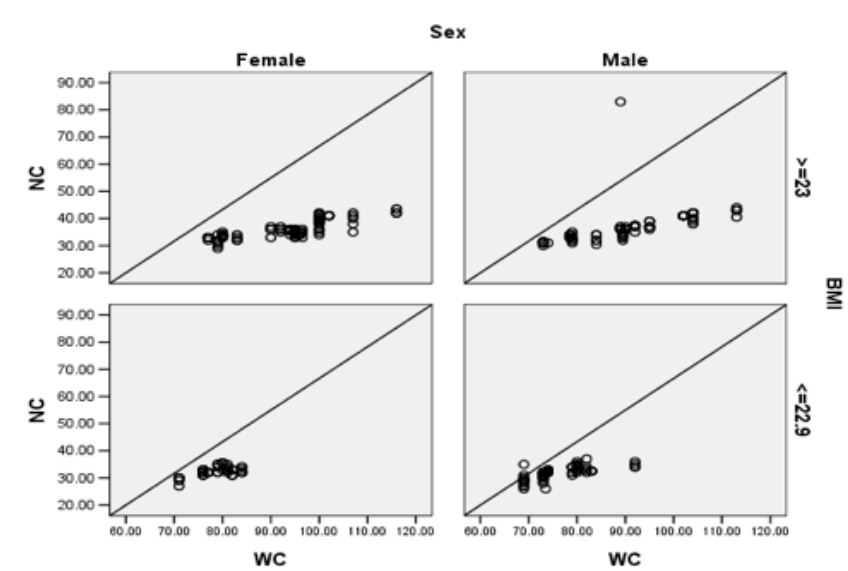

Figure 1. Scatter plot showing correlation ( $r$ ) of neck circumference $(\mathrm{cm})$ with waist circumference $(\mathrm{cm})$ in different body mass index (BMI) in male and female participants

\section{DISCUSSION}

There is strong correlation between neck and waist circumference in present study. In our study, NC (neck circumference) cutoff for abnormal waist ( $\geq 80 \mathrm{~cm}$ for female and $\geq 90 \mathrm{~cm}$ for male) was found $(32.5 \mathrm{~cm}$ for female and 34.7 $\mathrm{cm}$ formale). Mean neck circumference of $34.6 \pm 5.4 \mathrm{~cm}$ in males and $35.2 \pm 3.4 \mathrm{~cm}$ in females with mean waist circumference of $84.30 \pm 11 \mathrm{~cm}$ in male and $89.48 \pm 11.1 \mathrm{~cm}$ in female. Our result is comparable to the study from Pakistan where overweight defined by $\mathrm{BMI} \geq 23 \mathrm{~kg} / \mathrm{m} 2$ corresponded to waist values of $84.2 \pm 1.7 \mathrm{~cm}$ in males and $80.7 \pm 4.7 \mathrm{~cm}$ in females had neck circumferencevalues $35.7 \pm 0.4 \mathrm{~cm}$ in males and $32.2 \pm 0.9 \mathrm{~cm}$ in females and obesity defined by BMI $\geq 25$ corresponded to waist of $92.8 \pm 2.1 \mathrm{~cm}$ in males and $85.8 \pm 4.8 \mathrm{~cm}$ in females had neck circumferencevalues $37.5 \pm 0.8 \mathrm{~cm}$ in males and 33.5 $\pm 0.9 \mathrm{~cm}$ in females. ${ }^{17}$

In contrast to other studies, female from this study had higher neck circumference value than in male which could be explained by the obese BMI and abnormal waist of females. 
With similar average value of neck circumference, females had higher BMI and waist than males which support the higher cutoff neck circumferencein males. This is further supported by a Chinese studywhere cutoff points of neck circumference for overweight and obesity were $35.5 \mathrm{~cm}$ and $37.5 \mathrm{~cm}$ for men and $32 \mathrm{~cm}$ and $33.5 \mathrm{~cm}$ for women. ${ }^{6}$ But higher neck circumference cutoff for overweight and obesity was reported from Egypt. ${ }^{18}$ This could be because they used the higher BMI and waist cutoff to define overweight and obesity.

Our results showed statistical strong positive correlation of neck circumferencewith waist $(r>0.6)$ and positive correlation( $r>0.5)$ with $\mathrm{BMI}$, hip circumference and weight in all subjects except waist hip ratio which was applicable on males only and poor positive correlation with the height in both male and females. Similarly, neck circumferencehad strong positive correlation with waist $(r>0.8)$ in females with high BMI $(\geq 23 \mathrm{~kg} / \mathrm{m} 2)$.This signify the linear correlation of neck circumferencewith waist in obese/overweight individuals. Similar significant positive correlation of neck circumferencewith BMI and waist was found by Mozaffer in Pakistan. ${ }^{17}$ Several other studies had also reported the positive correlation of NC with waist and BMI.6, 19-21

There are few studies about wrist circumference in the literature. In present study, mean wrist circumference was found higher in males similar to a Turkish study ${ }^{22}$ but they had higher value than ours. Lower value in our study could be due to different ethnic population.

We found positive correlations of wrist circumference with BMI, waist and hip circumference, but strong positive correlation was found with weight in both sexes. The positive correlation of wrist circumference with weight, waist and BMI is supported by a study from Pakistan ${ }^{23}$ and Turkey. ${ }^{22}$ All of these new findings attracted attention to wrist circumference as a possible risk factor for developing diabetes, metabolic syndrome and cardiovascular diseases.

\section{REFERENCES}

1. Vischer T,Seidell JC.The public health importance of obesity.Ann Rec public health 2001;22:355- 75.

2. Kahn BB,Flier JS.Obesity and insulin resistance. J Clin Invest 2000; 106:473- 81

3. Grinsberg HN.Insulin resistance and cardiovascular diseases. J Clin Invest 2000; 106:453- 8.

4. Chan D C, Watts G F, Barrett P H et al. Waist
In present study, Our result showed higher prevalence of obesity and overweight which is in agreement with the studies where high prevalence of overweight and obesity was found in Nepalese population. ${ }^{24,25}$

According to our study results, both neck and wrist circumference seemed to be useful obesity measurement parameters for both male and female subjects. The study has some limitations that need to be addressed in future research. First, the sampling was not random and sample size was small consisting of healthy adults from a selected population and, therefore, the results cannot be generalized over the whole population. Second, because of less number of participants with normal range BMI, neck circumference cutoff for normal BMI could not find out.

Despite the limitations, the study has important implications for prevention of overweight and obesity in adults as it points towards the practical usage of an easier alternative for obesity measurement. Neckand wrist circumference have been shown to independently contribute to the prediction of overweight and obesity and can be used as an initial screening tool for the purpose. It is a straightforward and inexpensive test that can be performed in any office with a tape measure without undressing.

\section{CONCLUSION}

In conclusion, neck circumference had positive correlation with waist circumference in both genders. Neck circumference cutoff for abnormal waist was $34.4 \mathrm{~cm}$ for male and $32.5 \mathrm{~cm}$ for female. It still requires further investigations for the classification of its' definite position in obesity evaluation with growing new data on its possible role predicting metabolic and cardiovascular diseases. There is some relation of wrist measurement with waist, so present study is not sufficient to conclude its utility to determine the metabolic risk, but one can think about this and plan for large scale study.

circumference, waist-to-hip ratio and body mass index as predictors of adipose tissue compartments in men. QJM 2003; 96:441-47.

5. Misra A, Chowbey P, Makkar B M et al. Consensus Statement for Diagnosis of Obesity, Abdominal Obesity and the Metabolic Syndrome for Asian Indians and Recommendations for Physical Activity, Medical and Surgical Management.JAPI.2009; 57:163 -70.

6. Yang G, yuan S, Fu H et al. Neck circumference positively 
related with central obesity, overweight, and metabolic syndrome in Chinese subjects with type 2diabetes: Beijing community diabetes study. Diabetes care.2010; 33:2465-7.

7. Kissebach $A H$, Vydelinqum N, Murray $R$ et al. Relation of body fat distribution to metabolic complications of obesity. J ClinEndocrinol and Metab. 1982; 54:254-60.

8. Sjöström C D, Håkangård A C, Lissner L etal.Body compartment and subcutaneous adipose tissue distribution-risk factor patterns in obese subjects. ObesRes.1995; 3:9-22.

9. Sjöström C D, Lissner L, Sjöström L. Relationships between changes in body composition and changes in cardiovascular risk factors:The SOS Intervention Study. Swedish Obese Subjects. Obes Res. 1997; 5:519-30.

10. Jensen M D. Lipolysis: contribution from regional fat. Annu Rev Nutr. 1997; 17:127-39.

11. Dixon J B, O’Brien P E. Neck circumference a good predictor of raised insulin and free androgen index in obese premenopausal women: changes with weight loss.ClinEndocrinol. 2002; 57:769-78.

12. Marco C, Gaetano L, Antonio P et al. Wrist Circumference Is a Clinical Marker of Insulin Resistance in Overweight and ObeseChildren and Adolescents. Circulation. 2011; 123:1757-62.

13. Ben-Noun L L, Laor A. Relationship between changes in neck circumference and changes in blood pressure. Am J Hypertens. 2004; 17: 409-14.

14. Shrestha UK, Singh DL, Bhattarai MD. The prevalence of hypertension and diabetes defined by fasting and 2-h plasma glucose criteria in urban Nepal. Diabetic Medicine 2006; 23: 1130-35.

15. Sarah R, Michael J P, Ralph B D et al. Neck Circumference and Development of Cardiovascular Disease Risk Factors in the Framingham Heart Study.Circulation. 2009; 120 : 509.
16. World Health Organization. Measuring Obesity: Classification and Distribution of Anthropometric Data. Copenhagen: World Health Organization; 1989.

17. Mozaffer RH, Masood A Q, Asghar M. Neck circumference as a useful marker of obesity: A comparison with body mass index and waist circumference. J Pak Med Assoc2012; 62: 1.

18. Azzasarry el din, Nayerahassan, Sahar el-masry. Neck circumference as a simple screening measure for identifying egyptian overweight and obese adults. Macedonian Journal of Medical Sciences. 2013 Sep 15; 3:232-7.

19. Onat A, Hergenc $G$, Yuksel $H$ et al. Neck circumference as a measure of central obesity: associations with metabolic syndrome and obstructive sleep apnea syndrome beyond waist circumference.ClinNutr 2009;28: 46-51

20. Hatipoglu N, Mazicioglu M M, Kurtoglu S et al. Neck circumference: an additional tool of screening overweight and obesity in childhood. Eur J Pediatr 2010; 169: 733-9.

21. Nafiu O O, Burke C, Lee J et al. Neck circumference as a screening measure for identifying children with high body mass index. Pediatrics 2010; 126: 306-10.

22. Tatar B T, Ersoy C, Kacan T et al.Neck and Wrist Circumferences Propose a Reliable Approach to Qualify Obesity and Insulin Resistance.medscience. 2013; 2:8100.

23. Amini A, Soltanian N, Iraj B et al. Association of wrist circumference with cardio metabolic risk factors. J Pak Med Assoc. 2012; 3: 34-6.

24. Vaidya A, Pokharel PK, Nagesh S et al. Association of obesity and physical activity in adult males of Dharan, Nepal. Kathmandu University Medical Journal.2006; 4:192-7.

25. Rawat B, Malla S, VaidyaA et al. Coronary risk factors in apparently healthy individuals. Postgraduate Medical Journal of Nepal. 2001; 2: 56-8. 